\title{
The Application of the Information-gap Principle in Promoting English Language Skills in College English Teaching
}

\author{
Xiangwu LI \\ Department of Foreign Languages, Ankang University, Ankang, Shaanxi, 725000, China \\ Email: lxw.thjl@163.com
}

\begin{abstract}
As one of the basic principles in communicative language teaching (CLT), Information-gap Principle (IGP) is also attached great importance to by some college English teachers nowadays in China. This paper has concentrated on expounding the roles of IGP in college English teaching (CET). The Information-gap Principle plays an important role and its application in promoting English langue skills in CET should not be ignored by college teachers.
\end{abstract}

Keywords_-Information-gap Principle; college English teaching; communicative language teaching

\section{INTRODUCTION}

Since language is the vehicle for human communication, the goal of language teaching should be considered to enable learners to gain communicative competence. In communicative language teaching (CLT), the Information-gap Principle plays an important role, and it is the existing information gap that makes people feel necessary to communicate. By communication people may narrow or bridge the existing information gap and reach a balance of information. Once the former information gap is bridged, new information gap arises. In some sense the process of communication is like a circle of information gaps. By bridging the former information gap and creating new information gap, the communication continuum moves on. In college English teaching (CET), whether information gap exists or not in the teaching process is considered as a way to justify whether foreigner language is taught or learned as a tool for communication. Then it is the Information-gap Principle that most reflects the principle of communication strategy in CET.

\section{THE INFORMATION-GAP PRINCIPLE}

The phrase "information gap" is often mentioned in the discussion about communicative language teaching. It mainly refers to (in communication between two or more people) a situation where information is known by some of those present, i.e. different people hold different information or different level of information. In CLT, it is said that in order to promote the real communication between students, there must be an information gap between them, or between them and their teacher. Without such a gap, the classroom activities and exercises will be mechanical and artificial (Richards \& Rodgers, 1986).

The information gap just means the gap in the information people possess. Communication occurs only on condition that there are information gaps between the speaker and the listener; otherwise no real communication can be guaranteed. In the daily life, the information gap is automatic, disperse and aimless; while, in CET, the information gap should be well planned, proficiently managed and should contain a specific aim. That is to say, in CET, all the communicative activities should be planned and managed in such a way that may guarantee the information gap should exist. And the aim of both language and communication by the communicative process is to narrow or close the information gap.

\section{INFORMATION-GAP PRINCIPLE AND CET IN CHINA}

The history of Chinese research on Information-gap Principle can be traced back to over ten years ago. With the popularity of communicative language teaching in China, more and more English teachers begin to apply IGP to foreign language teaching, and college English education has made certain achievements. It is accepted that English needs to be taught and learned in a more communicative way. But what is the relationship between language and communication? The question might be put forward: Are we teaching language (for communication)? Are we teaching communication (via language)? According to Richard Allwright (1979), if communication is the aim, it should be the major element in the process. Richard (1979) also states that the two (teaching language for communication and teaching communication via language) are not directly incompatible, but there is a logical relationship between them.

Since communication is the major element in teaching process and the premise of communicative activities is information gap, the existence of information gap in CET can be regarded as an important mark in teaching language 
communicatively and can help to gain communicative competence. Therefore how teachers could improve the college students' communicative competence efficiently by applying IGP becomes a crucial problem.

\section{APPLICATION OF IGP IN PROMOTING ENGLISH LANGUAGE SKILLS IN CET}

The aim of language teaching courses is very commonly defined in terms of four skills: listening, speaking, reading and writing. In the following, the ways to design information-gap activities for speaking, listening, reading and writing are going to be discussed respectively.

Most CET students already have had a certain high level of English language, especially those recently enrolled college students. They expect a heavier emphasis on practice and communicative activities than on language-points presentation. "Whatever activity the students are involved in, if it is to be genuinely communicative and if it is really promoting language use, the students should have a desire to communicate" (Harmer, 1991). In handling the courses for developing students' four skills, there are two points that the teacher must keep in mind. One is to try to design as many communicative activities inside and outside class as possible; another is, and this is more important, to try to guarantee the communicative activities are appealing to students. And the way to guarantee this is to design communicative activities based on IGP. In the following, the ways to design information-gap activities for speaking / listening and information-gap activities for reading / writing are going to be discussed respectively.

\section{A. Information-gap Activities for Speaking/Listening Practice}

Traditionally, a speaking dialogue practice is provided in such a way that students A and B are fully aware of what each would say before the dialogue begins. Although this type of language practice has some value, it does not go far enough. On the one hand, speaking is separated from listening; on the other hand, there is no information gap between the speaker and the listener. Therefore, the college English teachers, in order to promote CET, should not only consider the combination of speaking and listening, but also the application of IGP in class activities. Information-gap activities are designed to take the students further towards being able to handle more realistic communications.

At the start of an information-gap activity, each pair of students are provided with similar but different information, usually on handouts labeled A and B. Then they are permitted to exchange information by using relevant language without looking at each other's handouts. So by the end of the interchange they are both in possession of the total amount of information. Since they do not know in advance what information they are going to receive in reply to their questions, students must have strong enthusiasm in doing such information interchange activities. The following cases are examples of information-gap activities for listening/speaking.

\section{Case 1: Find the differences (or similarities)}

Students are put into pairs. In each pair, Student A is given a picture and Student $\mathrm{B}$ is also given a picture, which is similar, but different in some vital respects. They are told that they must not look at each other's material but that they must find out a certain number of differences between the two pictures through discussion only.

\section{Case 2: Describe and arrange}

Students are told they are going to work in pairs. In each pair, Student $\mathrm{A}$ is given a picture and told not to show it to Student B. Then Student B's job is to arrange the picture in the same order as Student A tells him (or her).

\section{Case 3: Story reconstruction}

Students are let to listen to different parts of a story. Then they have to reconstruct the whole story even though individually they have listened to only a part of it. This job must be done through discussion among members of the whole class since each member has listened to part of the whole story.

But when using information-gap activities there are a number of points to bear in mind:

1) Careful preparation: The students cannot be expected to do this type of activity successfully without very careful preparatory work. Information-gap exercises can be devised to give tightly controlled or freer practice of exponents of one or more functions. The exponents need first to be presented or revised and the students given sufficient controlled practice: this lays the necessary foundations for the information-gap activity that is to follow.

2) Pre-teaching of vocabulary: When students are working in closed pairs, they should be allowed to get on with the task in hand without unnecessary interruption. If the teacher is aware that some of the vocabulary needed for the activity is likely to be unfamiliar to all or some of the students, it should be taught beforehand. This ensures that the flow of the activity is not interrupted.

3) Clear instructions: Students unused to doing pair work of this type need training in mechanics of the activity. Instructions need to be crystal clear to ensure that all students know what to do (e.g. it is best if each pair swivels round to face each other; they should know who is A and who is B: they should not look at each other's handouts; it should be clear whether they have to jot something down and where). In a monolingual class, the instructions might well be given in the mother tongue.

4) Demonstration: It is wise, especially with a class that is unfamiliar with this type of activity, to demonstrate a part of it to the whole class. The teacher can play $\mathrm{A}$ and a good student can play $B$, and then the first part of the task can be worked through. This should provide a clear model for all the other students before they set to work in their closed pairs.

5) Mixed ability: Most CET teachers have large groups of students with different aptitudes for learning languages, different degrees of motivation and very different levels of 
ability. There exists no magic solution to these problems. It helps, however, to foster, as far as possible, a cooperative atmosphere whereby better students are encouraged to help the less competent ones. This particularly applies to pair work. The teacher needs, however, to be sensitive to the students' whishes and not dictatorially impose unpopular pairs which will be counter-productive.

6) Use of the mother tongue: In monolingual classes, it is natural for the students to break into their own language, either during an activity, (e.g. when a difficulty arises) or more especially when they have finished an activity before other students. It is helpful if the teacher gently insists over a period of time on only English being used; also, a silent extension activity, e.g. a follow-up writing task, ensures that students who finish first have something else to do.

7) The teacher's role: After carefully setting up the activity, the teacher should first quickly check that each pair is in fact doing the activity in the intended, and then circulate again, listening samples of the oral work of as many pairs as possible. On-the-spot correction should be cut down to minimum as it is usually interpreted as an unwelcome interruption, but a mental note should be made of the recurring errors for later attention.

\section{B. Information-gap Activities for Reading and Writing}

According to Widdowson (1991), reading and writing are said to be related to language expressed through the visual medium. Both of them are exercises dominated by the eyes and the brain, so it is up to the reader (or writer) to decide how fast he or she can read (or write), and this is clearly a huge advantage for information-gap activities. But reading and writing cannot be considered as reciprocal activities in the same sense as are speaking and listening. Usually, what is written does not directly depend on a previous reading actively and a particular act of writing is not necessarily prompted by a particular act of reading. Therefore, it seems a bit difficult to convince English teachers that reading and writing can also be well taught in the same communicative way as in teaching speaking and listening.

Frequently, reading and writing are relegated to the status of some exercise practices. This is a pity since reading and writing teaching in communicative way can play a valuable part in the class. Information-gap activities are designed to help teachers to be able to handle these two courses more communicatively. The following example provides a way to design information-gap activities for reading/writing.

At the beginning of the activity, each pair of students is given the same but different parts of a reading material. After they finish reading their parts, they are asked to write down briefly what they have read. They are required to use as many expressions they have just learned in their reading materials as possible in their writing. While doing their own job, they may try to predict what is to come or what has proceeded by reference to their own reading part. If possible, they'd better write down their predictions. Then they exchange their writings in order to be in possession of the whole information and check whether their prediction is right. Since they don't know in advance what information is contained in the other part, they must be interested in reading their partner's writing and find out whether their prediction is coincident with the information provided by their partners. If they feel puzzled about some information, they may read together with their partners until they have scanned out what they want.

When doing the information-gap activities for reading / writing, the same points as for speaking and listening practice mentioned above should be kept in mind.

Just now the information-gap activities for the four skills have been discussed, but it does not mean that is the only way to carry out IGP in managing the class for developing students' four skills in CET. There are still many other ways. In fact, information gaps always exist between the teacher and students as well as among students themselves. If the teacher is sensitive to making use of them and deliberately creating information gaps in his (or her) classroom, he (or she) may be said not far from dealing with his (or her) classes communicatively.

\section{CONCLUSION}

The ultimate goal of college English teaching (CET) is to develop the learners' communicative competence in order for them to cope with the increasing communicative needs in today's fast changing world. However, the present situation of CET seems in China to be far from this goal. Since the information gap is a necessary element that motivates into communication, it will surely have a place in CET. Therefore, it is necessary for teachers and learners to have an idea about the Information-gap Principle, since information gap is the premise and motivation for people to communicate each other.

\section{REFERENCES}

[1] R. L. Allwright, "Language learning through communication practice”, in Brunfit \& Johnson (eds.) The communicative approach to language teaching. OUP, 1979.

[2] J. Harmer, The practice of English language teaching. Longman: Longman, 1991.

[3] J. Richards \& T. Rodgers, Approaches and Methods in Language Teaching: A Description and Analysis. Cambridge: CUP, 1986.

[4] H. G.Widdowson, Aspects of Language Teaching. London: OUP, 1991. 